\title{
Evaluation of perceived fears of COVID-19 virus infection and its relationship to health-related quality of life among patients with diabetes mellitus in Egypt during pandemic: a developing country single-center study
}

\author{
Mohamed Abdelghani $^{1,2}$ (D) $\cdot$ Mohamed G. Hamed $^{3} \cdot$ Amira Said $^{4} \cdot$ Eman Fouad $^{1}$
}

Received: 25 March 2021 / Accepted: 5 May 2021 / Published online: 12 May 2021

(c) The Japan Diabetes Society 2021

\begin{abstract}
Aims/introduction COVID-19 pandemic and its associated circumstances had adversely affected patients with chronic diseases. This study aimed to assess the health-related quality of life (QoL), and identify its psychological and clinical correlates in patients with diabetes mellitus (DM) during pandemic in Egypt.

Materials and methods A cross-sectional study, using a convenience sampling technique, was conducted among patients with DM who were recruited from Zagazig University endocrinology outpatient clinics, Sharkia Province, Egypt from June 30 to September 29,2020. A total of 200 consecutive patients were interviewed using a semistructured demographic and clinical checklist, the fear of COVID-19 scale (FCV-19S), the Hospital Anxiety and Depression Scale (HADS), and the short form 36 (SF-36) health survey.

Results Poor physical and mental QoL was reported in $64 \%$ and $62 \%$ of patients with DM, respectively. Female gender, increased mean arterial pressure (MAP), associated physical comorbidities, and depressive symptoms were associated with lesser odds of physical QoL (OR 0.46, 0.96, 0.29, and 0.88, respectively). Besides, female gender, associated physical comorbidities, fear of COVID-19 virus infection (FCV), and depressive symptoms were associated with lesser odds of mental QoL (OR 0.41, 0.36, 0.91, and 0.84, respectively). The FCV was inversely correlated with all items of SF-36 among patients.

Conclusion QoL, either physical or mental, was adversely affected among patients with DM during pandemic. FCV was negatively correlated with all QOL domains. Longitudinal studies are warranted to explore the long-term effect of pandemic on the physical and mental well-being of patients with DM.
\end{abstract}

Keywords COVID-19 pandemic $\cdot$ Diabetes mellitus $\cdot$ Quality of life $\cdot$ SF-36 health survey $\cdot$ Egypt

$\begin{array}{lll}\text { Abbreviations } & \text { HADS } \\ \text { COVID-19 } & \text { Coronavirus disease } & \text { HRQoL } \\ \text { DM } & \text { Diabetes mellitus } & \text { MAP } \\ \text { FCV } & \text { Fear of COVID-19 virus infection } & \text { MCS } \\ \text { FCV-19S } & \text { Fear of COVID-19 scale } & \text { PCS } \\ & & \text { QoL }\end{array}$

Mohamed Abdelghani

abdelghanim@alumni.vcu.edu

1 Psychiatry Department, Faculty of Medicine, Zagazig University, PO Box 44519, Zagazig, Egypt

2 Department of Psychology, Virginia Commonwealth University, Richmond, USA

3 Department of Internal Medicine, College of Medicine, Zagazig University, Zagazig, Egypt

4 Department of Anesthesia and Surgical Intensive Care, College of Medicine, Zagazig University, Zagazig, Egypt
Hospital Anxiety and Depression Scale Health-related quality of life

Mean arterial pressure

Mental Component Summary

Physical Component Summary

Quality of life

SARS-CoV-2 Severe acute respiratory syndrome coronavirus 2

SF-36 Short form 36 health survey

\section{Introduction}

Severe acute respiratory syndrome coronavirus 2 (SARSCoV-2), a novel coronavirus causing coronavirus disease (COVID-19), was first identified in Wuhan, China in 
December 2019 and had been considered the biggest threat to global public health for 2020. On March 11, 2020, World Health Organization declared COVID-19 as a pandemic [1]. It was stated that patients with pre-existing medical diseases as diabetes mellitus (DM), hypertension, and malignancies are considered as one of the highest at-risk groups for infection with novel coronavirus with increased severity and mortality [2]. Case-fatality ratio (CFR) was found to be higher in patients with cardiovascular diseases (10.5\%), DM $(7.3 \%)$ and hypertension (6\%) than that of general population $(2.3 \%)$ [3].

DM is defined as a chronic progressive metabolic disorder, which according to the underlying pathology is subdivided into type 1 or type $2 \mathrm{DM}$, caused by an absolute or relative deficiency of insulin hormone, respectively [4]. According to the International Diabetes Federation (IDF) Atlas edition released in 2012, the global estimates of DM were more than 380 million people, and these numbers are expected to double by 2030 [5]. Patients with DM are suffering from physical complications (cardiovascular diseases, neuropathy, diabetic foot, nephropathy, etc.). In addition, their social lives are greatly affected (e.g., glycemic control and changes in dietary habits and lifestyle) [6]. Moreover, psychological complications may also occur in patients with DM [7, 8]. Psychiatric disturbances commonly associated with DM included depression and anxiety symptoms (2-4 times greater than the general population) [9]. These comorbid disturbances could be exacerbated in a stressful environment. It was claimed that the novelty and uncertainty of the COVID-19 pandemic would increase psychological distress, anxiety, and depression with adverse outcomes among the general population [10]. Patients with DM were found to experience higher levels of stress, anxiety, and depression compared to their healthy counterparts during the COVID19 outbreak [11].

The patients' self-care behaviors, disease management and lifestyle, and therapeutic compliance are influenced by the physical, psychological, and social burden of DM, which would eventually affect the quality of life (QoL) among those populations [12]. Health-related quality of life (HRQoL) is a multidimensional construct based on a person's physical, cognitive, social, emotional, psychological, role, and spiritual status. Several studies reported that the QoL of patients with DM, which is perceived as an acceptable outcome or efficacy of self-care among those patients, is lower than that of the general population [13-15].

It would be claimed that the psychosocial consequences of the COVID-19 pandemic add to the burden of psychosocial problems of people with DM and cause more negative effects on their HRQoL. To our knowledge, limited studies have investigated the mental health and HRQoL of people with chronic diseases specifically with DM in Egypt, as one of the middle-east developing countries, during the pandemic. In that context, this study would be one of the earliest studies, if any, to investigate the impact of the COVID19 pandemic on HRQoL and identify its psychological and clinical correlates among patients with DM in Egypt.

\section{Subjects and methods}

\section{Study design and sampling}

This was a cross-sectional study conducted among a sample of 200 patients with DM who were recruited from the endocrinology outpatient clinics at Zagazig University, Zagazig City, Sharkia Province, Egypt during the period from June 30 to September 29, 2020. A nonprobability convenience sampling method was used to collect the sample. The Epi Info 6.0 was applied to calculate the sample size, at $80 \%$ power of the study, 95\% confidence level. Patients, included in the study, were adults aged more than 18 years, of both sexes, diagnosed with type 1 and type 2 diabetes, attended the outpatient clinics for regular follow-up, and able to understand and communicate and accepted to participate in this study. Patients with cognitive/neurological impairment, mental/physical disability, severe complications, or refusing to participate or complete the study were excluded.

\section{Assessment tools}

\section{Exposure ascertainment}

The primary exposure variable was the perceived fear of COVID-19 virus infection (FCV) among patients with DM. The intensity of these fears was assessed using the Fear of COVID-19 scale (FCV-19S) [16]. FCV-19 consisted of 7 questions with answers of strongly disagree $=1$, disagree $=2$, neither agree nor disagree $=3$, agree $=4$, and strongly agree $=5$ with total score ranged from 7 to 35 . The higher scores of FCV-19S indicated higher levels of fears and worries of COVID-19 virus infection. The Arabic version of this scale, used in this study, was translated and its reliability and validity were previously examined [17].

\section{Outcome ascertainment}

The primary outcome assessed was the HRQoL among patients with DM. The 36-Item Short-Form Health Survey questionnaire (SF-36) was used in this study for evaluating HRQoL [18]. The SF-36 was composed of eight subscales namely physical functioning (PF), role physical (RP), bodily pain (BP), general health (GH), vitality (VT), social functioning (SF), role emotional (RE), and mental health (MH). The raw scores were transformed into scales ranging from 0 to 100 . The higher scores denoted higher or good HRQoL. 
Additional two distinct concepts measured by the SF-36, according to component analyses, were also shown. Physical Component Summary (PCS) included the sum of the subscales representing the physical dimension, while the Mental Component Summary (MCS) included the sum of the subscales representing the mental/psychological dimension. This questionnaire was a free domain survey developed and translated into Arabic by the RAND Corporation with equivalent reliability [19]. The Arabic version of SF-36 was utilized in this study.

\section{Covariates}

They included sociodemographic and clinical variables and associated psychiatric symptoms (depression and anxiety). A semistructured checklist was designed to collect demographic and clinical data regarding the general health status and DM. Demographic data included age, gender, and smoking status, while, clinical data included duration of $\mathrm{DM}$, body mass index (BMI), Hb A1c, mean arterial blood pressure (MAP), type of DM treatment (oral or insulin), previous history of psychiatric illnesses, presence of other chronic medical illnesses, Family history of DM, Adherence to diet, exercise, treatment, and glucose testing, and presence of DM complications.

Associated symptoms of anxiety and depression were screened using the Hospital Anxiety and Depression Scale (HADS). This self-rated tool was utilized to investigate the associated symptoms of anxiety and depression among participants [20]. The scale encompassed 14 items; half of them assess the level of anxiety symptoms and the other half assess the level of depressive ones. Answer to each question ranged from 0 to 3 in a Likert-like format. The lowest score for either anxiety or depression subscale was 0 and the highest score was 21 . Valid cases of depression or anxiety symptoms were considered if scores were equal to or exceed 11. The Arabic version, used in this study, was translated and examined for its reliability and validity [21].

\section{Statistical analyses}

Statistical Package for the Social Sciences was utilized to analyze the data (SPSS, version 22.0, Chicago, IL) software. Qualitative variables were described by frequency distributions, and the Chi-square test was used to compare the proportions of categorical data, while quantitative variables were described by the means and standard deviations, and the independent sample $t$ test was used to compare the means of two groups. To evaluate the degree of relationship between two variables with a linear relationship, the Pearson correlation coefficient was used. A nonparametric test (Mann-Whitney) was used to compare the means when data were not normally distributed. Logistic regression analysis was used to identify the potential predictors of PCS and MCS in patients with DM. All results were considered statistically significant when the significant probability was less than 5\% $(p<0.05)$.

Approval of the research proposal was provided by Zagazig University Institutional Review Board (IRB no. 6204-6-27-2020, Approval date; June 27, 2020). All participants were invited to sign informed written consent after confirming confidentiality and discussing all objectives and procedures utilized in this study.

\section{Results}

\section{Sociodemographic and clinical characteristics of study participants}

This study included 200 patients diagnosed with DM of both sexes. The mean age of the participants was $48.4 \pm 13.7$ years, and the mean duration of illness (DM) was $6.2 \pm 5.3$ years. The majority were females $(n=126$, $63 \%)$, nonsmokers $(n=164,82 \%)$, treated with oral hypoglycemic agents $(n=118,59 \%)$, and having family history of DM $(n=172,86 \%)$. About one-fourth of patients reported a history of comorbid psychiatric disorders, while more than three-fourths reported a history of other physical comorbidities. Around half of the patients reported at least one diabetic complication like peripheral neuropathy, retinopathy, or nephropathy $(n=93,47 \%)$.

Regarding HRQoL assessed by the SF-36 scores, 64\% $(n=128)$ and $62 \%(n=124)$ of patients with DM reported poor PCS and MCS, respectively. Those with poor PCS were disproportionately females $(72 \%, P$ value $=0.001)$, having higher MAP $(96.8 \pm 10.9, P$ value $<0.001)$, history of other physical comorbidities $(86 \%, P$ value $<0.001)$, diabetic complications $(52 \%, P$ value $=0.040)$, and higher levels of FCV $(20.6 \pm 6.6, P$ value $=0.001)$, depressive $(10.1 \pm 3.9, P$ value $<0.001)$, and anxiety symptoms $(9.8 \pm 3.8, P$ value $<0.001)$. On the other hand, those with poor MCS were disproportionately older $(51.5 \pm 12.4$ years, $P$ value $<0.001)$, females $(73 \%, P$ value $<0.001)$, having higher MAP $(96.0 \pm 11.8, P$ value $=0.016)$, history of other physical comorbidities $(84 \%, P$ value $=0.001)$, family history of DM $(90 \%, P$ value $=0.024)$, diabetic complications $(50 \%, P$ value $=0.047)$, poor adherence to glucose testing $(52 \%, P$ value $=0.042)$, and higher levels of FCV $(21.3 \pm 3.6, P$ value $<0.001)$, depressive $(10.3 \pm 3.6$, $P$ value $<0.001)$, and anxiety symptoms $(9.8 \pm 3.9, P$ value $<0.001)$, as illustrated in Tables 1 and 2 . 
Table 1 Characteristics of patients with DM during pandemic according to Physical Component Summary (PCS)

\begin{tabular}{|c|c|c|c|c|c|c|c|c|c|}
\hline \multicolumn{2}{|l|}{ Variables } & \multicolumn{2}{|l|}{$\begin{array}{l}\text { Poor } \\
(n=128)\end{array}$} & \multicolumn{2}{|l|}{$\begin{array}{l}\text { Good } \\
(n=72)\end{array}$} & \multicolumn{2}{|l|}{ Total } & $t$ & $P$ value \\
\hline \multicolumn{10}{|l|}{ Age } \\
\hline \multirow[t]{2}{*}{ Mean \pm SD } & & $49.4 \pm 13.1$ & & $46.6 \pm 14.8$ & & $48.4 \pm 13.7$ & & 1.40 & 0.164 \\
\hline & & No & $\%$ & No & $\%$ & No & $\%$ & $\chi^{2}$ & \\
\hline \multicolumn{10}{|l|}{ Gender } \\
\hline \multicolumn{2}{|l|}{ Male } & 36 & 28.1 & 38 & 52.8 & 74 & 37.0 & 12.01 & 0.001 \\
\hline \multicolumn{2}{|l|}{ Female } & 92 & 71.9 & 34 & 47.2 & 126 & 63.0 & & \\
\hline \multicolumn{10}{|l|}{ Smoking status } \\
\hline \multicolumn{2}{|l|}{ Yes } & 22 & 17.2 & 14 & 19.4 & 36 & 18.0 & 4.13 & 0.062 \\
\hline \multirow[t]{2}{*}{ No } & & 106 & 82.8 & 58 & 80.6 & 164 & 82.0 & & \\
\hline & & & & & & & & MWU & \\
\hline Duration of illness (DM) & Mean \pm SD & $6.4 \pm 6.0$ & & $6.2 \pm 4.8$ & & $6.2 \pm 5.3$ & & -0.54 & 0.588 \\
\hline BMI & Mean \pm SD & $34.8 \pm 7.5$ & & $32.6 \pm 7.5$ & & $34.0 \pm 7.6$ & & 1.90 & 0.059 \\
\hline $\mathrm{Hb} \mathrm{A} 1 \mathrm{c}$ & Mean \pm SD & $8.1 \pm 1.6$ & & $7.8 \pm 1.7$ & & $8.0 \pm 1.7$ & & 1.31 & 0.191 \\
\hline MAP & Mean \pm SD & $96.8 \pm 10.9$ & & $90.4 \pm 10.3$ & & $94.5 \pm 11.1$ & & 3.92 & $<0.001$ \\
\hline \multicolumn{10}{|l|}{ Treatment of DM } \\
\hline \multicolumn{2}{|l|}{ Oral } & 72 & 56.3 & 46 & 63.9 & 118 & 59.0 & 1.11 & 0.292 \\
\hline \multicolumn{2}{|l|}{ Insulin } & 56 & 43.7 & 26 & 36.1 & 82 & 41.0 & & \\
\hline \multicolumn{10}{|c|}{ History of psychiatric illnesses } \\
\hline \multicolumn{2}{|c|}{ Yes } & 34 & 26.6 & 14 & 19.4 & 48 & 24.0 & 1.28 & 0.258 \\
\hline \multicolumn{2}{|l|}{ No } & 94 & 73.4 & 58 & 80.6 & 152 & 76.0 & & \\
\hline \multicolumn{10}{|c|}{ History of other chronic medical illnesses } \\
\hline \multicolumn{2}{|c|}{ Yes } & 110 & 85.9 & 42 & 58.3 & 152 & 76.0 & 19.25 & $<0.001$ \\
\hline \multicolumn{2}{|l|}{ No } & 18 & 14.1 & 30 & 41.7 & 48 & 24.0 & & \\
\hline Family history of DM & & & & & & & & & \\
\hline Yes & & 114 & 89.1 & 58 & 80.6 & 172 & 86.0 & 2.77 & 0.096 \\
\hline No & & 14 & 10.9 & 14 & 19.4 & 28 & 14.0 & & \\
\hline Adherence to diet & & & & & & & & & \\
\hline Good & & 84 & 65.6 & 50 & 69.4 & 134 & 67.0 & 0.30 & 0.581 \\
\hline Poor & & 44 & 34.4 & 22 & 30.6 & 66 & 33.0 & & \\
\hline Adherence to exercise & & & & & & & & & \\
\hline Good & & 22 & 17.2 & 18 & 25.0 & 40 & 20.0 & 1.76 & 0.185 \\
\hline Poor & & 106 & 82.8 & 54 & 75.0 & 160 & 80.0 & & \\
\hline Adherence to treatment & & & & & & & & & \\
\hline Good & & 100 & 78.1 & 58 & 80.6 & 158 & 79.0 & 0.16 & 0.685 \\
\hline Poor & & 28 & 21.9 & 14 & 19.4 & 42 & 21.0 & & \\
\hline Adherence to glucose test & & & & & & & & & \\
\hline Good & & 66 & 51.6 & 42 & 58.3 & 108 & 54 & 0.85 & 0.356 \\
\hline Poor & & 62 & 48.4 & 30 & 41.7 & 92 & 46 & & \\
\hline Presence of DM complic & & & & & & & & & \\
\hline Yes & & 67 & 52.3 & 26 & 36.1 & 93 & 46.5 & 3.59 & 0.040 \\
\hline No & & 61 & 47.7 & 46 & 63.9 & 107 & 53.5 & & \\
\hline FCV & Mean \pm SD & $20.6 \pm 6.6$ & & $17.3 \pm 6.2$ & & $19.4 \pm 6.7$ & & 3.38 & 0.001 \\
\hline HADS Scoring & Mean \pm SD & & & & & & & MWU & \\
\hline Depression & & $10.1 \pm 3.9$ & & $7.0 \pm 3.5$ & & $8.9 \pm 4.5$ & & -5.19 & $<0.001$ \\
\hline Anxiety & & $9.8 \pm 3.8$ & & $7.1 \pm 4.8$ & & $8.8 \pm 4.4$ & & -4.40 & $<0.001$ \\
\hline
\end{tabular}

$B M I$ body mass index, $D M$ diabetes mellitus, $F C V$ fear of COVID-19 virus infection, $H A D S$ Hospital Anxiety and Depression Scale, $M A P$ mean arterial pressure, PCS Physical Component Summary 
Table 2 Characteristics of patients with DM during pandemic according to Mental Component Summary (MCS)

\begin{tabular}{|c|c|c|c|c|c|c|c|c|c|}
\hline \multicolumn{2}{|l|}{ Variables } & \multicolumn{2}{|l|}{$\begin{array}{l}\text { Poor } \\
(n=124)\end{array}$} & \multicolumn{2}{|l|}{$\begin{array}{l}\text { Good } \\
(n=76)\end{array}$} & \multicolumn{2}{|l|}{ Total } & $t$ & $P$ value \\
\hline \multicolumn{10}{|l|}{ Age } \\
\hline \multirow[t]{2}{*}{ Mean \pm SD } & & $51.5 \pm 12.4$ & & $43.4 \pm 14.5$ & & $48.4 \pm 13.7$ & & 4.21 & $<0.001$ \\
\hline & & No & $\%$ & No & $\%$ & No & $\%$ & $\chi^{2}$ & \\
\hline \multicolumn{10}{|l|}{ Gender } \\
\hline \multicolumn{2}{|l|}{ Male } & 34 & 27.4 & 40 & 52.6 & 74 & 37.0 & 12.85 & $<0.001$ \\
\hline \multicolumn{2}{|l|}{ Female } & 90 & 72.6 & 36 & 47.4 & 126 & 63.0 & & \\
\hline \multicolumn{10}{|l|}{ Smoking } \\
\hline \multicolumn{2}{|l|}{ Yes } & 20 & 16.1 & 16 & 21.6 & 36 & 18.0 & 7.03 & 0.080 \\
\hline \multirow[t]{2}{*}{ No } & & 106 & 83.9 & 58 & 78.4 & 164 & 82.0 & & \\
\hline & & & & & & & & MWU & \\
\hline Duration of illness (DM) & Mean \pm SD & $6.4 \pm 5.0$ & & $6.0 \pm 5.7$ & & $6.2 \pm 5.3$ & & -1.23 & 0.219 \\
\hline BMI & Mean \pm SD & $34.4 \pm 7.3$ & & $33.3 \pm 8.1$ & & $34.0 \pm 7.6$ & & 0.99 & 0.324 \\
\hline $\mathrm{Hb} \mathrm{A} 1 \mathrm{c}$ & Mean \pm SD & $8.03 \pm 1.6$ & & $7.98 \pm 1.9$ & & $8.0 \pm 1.7$ & & 0.19 & 0.848 \\
\hline MAP & Mean \pm SD & $96.0 \pm 11.8$ & & $91.9 \pm 9.3$ & & $94.5 \pm 11.1$ & & 2.44 & 0.016 \\
\hline \multicolumn{10}{|l|}{ Treatment of DM } \\
\hline \multicolumn{2}{|l|}{ Oral } & 70 & 56.5 & 48 & 63.2 & 118 & 59.0 & 0.88 & 0.349 \\
\hline \multicolumn{2}{|l|}{ Insulin } & 54 & 43.5 & 28 & 36.8 & 82 & 41.0 & & \\
\hline \multicolumn{10}{|c|}{ History of psychiatric illnesses } \\
\hline \multicolumn{2}{|c|}{ Yes } & 26 & 21.0 & 22 & 28.9 & 48 & 24.0 & 1.65 & 0.200 \\
\hline \multicolumn{2}{|l|}{ No } & 98 & 79.0 & 54 & 71.1 & 152 & 76.0 & & \\
\hline \multicolumn{10}{|c|}{ History of other chronic medical illnesses } \\
\hline \multicolumn{2}{|l|}{ Yes } & 104 & 83.9 & 48 & 63.2 & 152 & 76.0 & 11.08 & 0.001 \\
\hline \multicolumn{2}{|l|}{ No } & 20 & 16.1 & 28 & 36.8 & 48 & 24.0 & & \\
\hline Family history of DM & & & & & & & & & \\
\hline Yes & & 112 & 90.3 & 60 & 78.9 & 172 & 86.0 & 5.06 & 0.024 \\
\hline No & & 12 & 9.7 & 16 & 21.1 & 28 & 14.0 & & \\
\hline Adherence to diet & & & & & & & & & \\
\hline Good & & 82 & 66.1 & 52 & 68.4 & 134 & 67.0 & 0.11 & 0.738 \\
\hline Poor & & 42 & 33.9 & 24 & 31.6 & 66 & 33.0 & & \\
\hline Adherence to exercise & & & & & & & & & \\
\hline Good & & 22 & 17.7 & 18 & 23.7 & 40 & 20.0 & 1.04 & 0.308 \\
\hline Poor & & 102 & 82.3 & 58 & 76.3 & 160 & 80.0 & & \\
\hline Adherence to treatment & & & & & & & & & \\
\hline Good & & 98 & 79.0 & 60 & 78.9 & 158 & 79.0 & 0.01 & 0.989 \\
\hline Poor & & 26 & 21.0 & 16 & 21.1 & 42 & 21.0 & & \\
\hline Adherence to glucose test & & & & & & & & & \\
\hline Good & & 60 & 48.4 & 48 & 63.2 & 108 & 54.0 & 4.14 & 0.042 \\
\hline Poor & & 64 & 51.6 & 28 & 36.8 & 92 & 46.0 & & \\
\hline Presence of DM complic & & & & & & & & & \\
\hline Yes & & 62 & 50.0 & 31 & 40.8 & 93 & 46.5 & 3.30 & 0.047 \\
\hline No & & 62 & 50.0 & 45 & 58.2 & 107 & 53.5 & & \\
\hline FCV & Mean \pm SD & $21.3 \pm 6.7$ & & $16.4 \pm 5.3$ & & $19.4 \pm 6.7$ & & 5.38 & $<0.001$ \\
\hline HADS Scoring & Mean \pm SD & & & & & & & MWU & \\
\hline Depression & & $10.3 \pm 3.6$ & & $6.7 \pm 3.6$ & & $8.9 \pm 4.5$ & & -5.68 & $<0.001$ \\
\hline Anxiety & & $9.8 \pm 3.9$ & & $7.2 \pm 4.6$ & & $8.8 \pm 4.4$ & & -4.28 & $<0.001$ \\
\hline
\end{tabular}

$B M I$ body mass index, $D M$ diabetes mellitus, $F C V$ fear of COVID-19 virus infection, HADS Hospital Anxiety and Depression Scale, $M A P$ mean arterial pressure, MCS Mental Component Summary 


\section{Predictors of poor PCS and MCS in patients with DM}

With logistic regression of all statistically significant variables among patients with DM, female gender (OR 0.46, 95\% CI $0.22,0.96$ for PCS, OR $0.41,95 \%$ CI $0.18,0.91$ for

Table 3 Adjusted logistic regression for predictors of PCS and MCS in patients with DM

\begin{tabular}{|c|c|c|c|c|}
\hline & \multicolumn{2}{|l|}{ PCS } & \multicolumn{2}{|l|}{ MCS } \\
\hline & OR $(95 \% \mathrm{CI})$ & $P$ value & OR $(95 \% \mathrm{CI})$ & $P$ value \\
\hline Age & & & $0.97(0.94-1.01)$ & 0.102 \\
\hline \multicolumn{5}{|l|}{ Gender } \\
\hline Male & 1.0 & 0.038 & 1.0 & 0.028 \\
\hline Female & $0.46(0.22-0.96)$ & & $0.41(0.18-0.91)$ & \\
\hline MAP & $0.96(0.92-0.99)$ & 0.021 & $1.01(0.97-1.04)$ & 0.913 \\
\hline \multicolumn{5}{|c|}{ History of other chronic medical illness } \\
\hline No & 1.0 & 0.003 & 1.0 & 0.040 \\
\hline Yes & $0.29(0.12-0.66)$ & & $0.36(0.14-0.95)$ & \\
\hline \multicolumn{5}{|c|}{ Family history of DM } \\
\hline No & & & 1.0 & 0.963 \\
\hline Yes & & & $0.97(0.30-3.12)$ & \\
\hline \multicolumn{5}{|c|}{ Adherence to glucose testing } \\
\hline Good & & & 1.0 & 0.071 \\
\hline Poor & & & $0.48(0.22-1.07)$ & \\
\hline \multicolumn{5}{|c|}{ Presence of DM complications } \\
\hline No & 1.0 & 0.228 & 1.0 & 0.438 \\
\hline Yes & $0.60(0.27-1.37)$ & & $0.68(0.26-1.79)$ & \\
\hline FCV & $0.98(0.92-1.04)$ & 0.479 & $0.91(0.85-0.97)$ & 0.008 \\
\hline Depression & $0.88(0.78-0.99)$ & 0.045 & $0.84(0.74-0.96)$ & 0.009 \\
\hline Anxiety & $0.92(0.84-1.02)$ & 0.101 & $0.99(0.89-1.09)$ & 0.793 \\
\hline
\end{tabular}

Bold text shows statistical significance where the $95 \%$ confidence intervals do not include the null value (1.0)

$D M$ diabetes mellitus, $F C V$ fear of COVID-19 virus infection, $M A P$ mean arterial pressure, MCS mental component summary PCS Physical Component Summary
MCS), history of other physical comorbidities (OR 0.29, 95\% CI 0.12, 0.66 for PCS, OR 0.36, 95\% CI 0.14, 0.96 for MCS), and depressive symptoms (OR $0.88,95 \%$ CI 0.78 , 0.99 for PCS, OR $0.84,95 \%$ CI $0.74,0.96$ for MCS) were shared predictors for both poor PCS and MCS. Besides, higher MAP scores (OR 0.96, 95\% CI 0.92, 0.99) predicted poor PCS, and higher levels of FCV (OR 0.84, 95\% CI 0.74, 0.96) predicted poor MCS, as illustrated in Table 3.

\section{Relationship between FCV and quality of life in patients with DM}

Table 4 illustrates the mean scores of the SF-36 items and their relationship to the fear of COVID-19 virus infection. The FCV scores were found to be inversely correlated with the eight items of SF-36.

\section{Discussion}

Outbreaks of infectious diseases were known to have negative health, social and economic impacts on both infected and non-infected individuals [22]. With the emergence of the COVID-19 pandemic, several studies had documented the adverse impact of COVID-19 and its containment measures on mental health and quality of life in COVID-19 patients, healthcare workers, patients with pre-existing psychiatric diseases, and the general population [23-26].

The main findings in this study were that during the COVID-19 pandemic, the majority of patients with DM experienced poor physical and mental QoL. Besides, the higher levels of COVID-19 related fear were found to be associated with poor HRQoL. It would be argued that the responses of the patients with DM in Egypt might be, in part, attributed to the fact that the QoL of millions of Egyptians were adversely affected due to the COVID-19 pandemic. Various studies, conducted in Egypt, had stated that not
Table 4 Scores of SF-36 items, and their correlation with FCV among patients with DM

\begin{tabular}{llrr}
\hline FCV-19S score & M (SD) & $\begin{array}{l}\text { Pearson correla- } \\
\text { tion }(r)\end{array}$ & $P$ value \\
\hline SF-36 items & & & $<0.001$ \\
Physical functioning & $55.2(27.1)$ & -0.25 & 0.001 \\
Role limitations due to physical health & $33.6(13.4)$ & -0.22 & $<0.001$ \\
Role limitations due to emotional problems & $35.3(14.7)$ & -0.29 & $<0.001$ \\
Energy/fatigue & $41.7(19.7)$ & -0.24 & $<0.001$ \\
Emotional well-being & $56.2(19.8)$ & -0.38 & $<0.001$ \\
Social functioning & $54.8(26.7)$ & -0.32 & 0.022 \\
Body pain & $49.1(13.6)$ & -0.16 & $<0.001$ \\
General health & $45.2(14.5)$ & -0.41 & \\
\hline
\end{tabular}

$D M$ diabetes mellitus, $F C V$ fear of COVID-19 virus infection, FCV-19S Fear of COVID-19 scale, $S F-36$ short form 36 health survey 
only patients with DM, but also healthcare workers, subjects with other chronic diseases, COVID-19 survivors, and even healthy subjects suffered from higher levels of emotional disturbances which negatively influenced the physical and mental aspects of their QoL during the pandemic [27-30].

However, owing to the chronic nature of DM, as well as the unique variables related to DM itself, it would be expected that the QoL of the Egyptian patients with DM would be more affected than other populations. The findings from previous studies documented that patients with DM had poor QoL compared to the normal population [31, 32]. With the emergence of the COVID-19 pandemic, patients with chronic diseases like DM and cardiovascular diseases had lower QoL, and the higher the number of associated chronic diseases the lower the score of QoL $[33,34]$. The poor QoL can be explained by increased levels of psychological distress, anxiety, depression, and stress caused by the increase in perceived susceptibility to infection and mortality risks among patients with chronic diseases during the pandemic $[10,35]$, delay and inaccessibility to medical services and treatment as a result of the COVID-19 pandemic [24], the lack of clarity about the relationship between COVID-19 and diabetes [36], avoidance of both urgent and routine medical care because of COVID-19 concerns by patients with chronic disease due to perceived risk of infection which may result in life-threatening medical emergencies [37], and lastly, sedentary behavior, physical inactivity and social isolation caused by the adaption of precautionary measures to combat COVID-19 virus infection [38].

The current study also found that the COVID-19-related fear was negatively linked to health-related quality of life among patients with DM. It was found that the fears of coronavirus (FCV) and associated stress were negatively linked to life satisfaction and QoL among the general population during the COVID-19 pandemic [26, 39]. However, patients with DM were found to have more worries and fears during the COVID-19 pandemic due to the perceived higher risk of infection [40]. These extensive fears and worries attributed to COVID-19 virus infection would be related to its novelty, rapid transmission, higher mortality rate, and confusion about the future [41]. Fears and uncertainty generated during pandemics increase stress and vulnerability, which, in turn, have a detrimental impact on subjective mental well-being [42].

Regarding the risk factors affecting the HRQoL, the current study stated that female gender, other physical comorbidities, and depressive symptoms were predictors for both poor physical and mental QoL among patients with DM. Previous studies stated that comorbid physical and psychiatric disorders particularly depression were associated with poor QoL among patients with DM [43, 44]. It was also found that women with COVID-19 had lower scores for HRQoL than men [34]. Conversely, few studies, conducted before the era of the COVID-19 outbreak, found no relationship between sex and HRQoL among patients with DM [45, 46]. Nonetheless, the worse QoL in women would be attributed to their lower level of physical activity, especially in developing countries [47], higher risk of complications [48], higher levels of depression and anxiety [49], and more worries about the disease with less ability to cope than men [34].

It is essential to highlight few limitations of the current study. First, this study involved a cross-sectional research design which would limit the ability to definitively infer causal relationships. Second, patients, in this study, were recruited from one central hospital, which would limit the generalizability of results. However, the authors argued that the Zagazig university hospitals were the largest general health facility located in Sharkia Province; the 2nd most populated province, after the Great Cairo region, in Egypt, with approximately 7.8 million inhabitants. Moreover, this study would be one of few studies, if any, in Egypt which focused on and assessed HRQoL among patients with DM during the COVID-19 pandemic. Nonetheless, future research warrants the conduction of multi-center large-sized longitudinal studies to avoid the aforementioned limitations. Third, mental health well-being and the patients, enrolled in this study, were not assessed for their QoL before the period of the COVID-19 pandemic for comparison with the current circumstances. Lastly, the absence of a control group (nondiabetic individuals) would be also claimed as another limitation in this study. However, the authors found it extremely difficult to recruit healthy subjects, as a control group, for two reasons. The first was that in accordance with the lockdown restrictions, the official authorities, in Egypt, banned unnecessary face-to-face contact or visits inside hospitals with healthy subjects. The second was that the authors had a major concern that recruitment of the close relatives of patients with DM, supposed to indirectly suffer from and the quality of their lives were undoubtedly influenced by the illness of the patients, as a control group would increase the liability of selection bias, the issue that would affect the reliability of the study results.

In conclusion, poor mental and physical HRQoL was evident in most patients with DM during the COVID-19 pandemic. In addition, higher levels of FCV were found to be correlated with more impairment in both physical and mental QoL. Female gender, history of other physical comorbidities, and associated depressive symptoms were predictors of poor physical and mental HRQoL among those patients. The study findings would represent an alarm for the potential impact of the pandemic on the QoL of patients with chronic diseases particularly DM, and highlight the need for routine screening for the associated fears, worries, and other mental and physical health-related issues. Adoption of certain strategies was necessitated during and after this pandemic including early monitoring, counseling, and 
psychotherapeutic interventions for the emerging psychiatric symptoms. Likewise, population-based longitudinal studies are warranted to identify the other possible long-term physical and psychological complications among patients with DM Egypt during the pandemic.

Acknowledgements All the authors would like to thank all subjects who participated in this study.

Author contributions All the authors contributed effectively to the conceptualization and work design of the current study. Analysis and interpretation of collected data were carried out by MA and MGH. Writing and editing of the manuscript were performed by EF and AS. All the authors have approved the final manuscript.

Funding This research did not receive financial support from any funding agencies.

Data availability The datasets utilized in this study are available from the corresponding author upon reasonable request.

\section{Declarations}

Conflict of interest All the authors declare that they do not have any conflicts of interest to disclose.

Ethical approval The study procedures were conducted within the ethical guidelines outlined in the Declaration of Helsinki and its later amendments.

Informed consent Informed consent was requested from all participants at the beginning of the present study.

\section{References}

1. Muniyappa R, Gubbi S. COVID-19 pandemic, coronaviruses, and diabetes mellitus. Am J Physiol Endocrinol Metab. 2020;318(5):E736-41.

2. Bai Y, Yao L, Wei T, Tian F, Jin DY, Chen L, et al. Presumed asymptomatic carrier transmission of COVID-19. JAMA. 2020;323(14):1406-7.

3. Wu Z, McGoogan JM. Characteristics of and important lessons from the coronavirus disease 2019 (COVID-19) outbreak in China: summary of a report of 72,314 cases from the Chinese center for disease control and prevention. JAMA. 2020;323(13):1239-42.

4. Al-Lawati JA, Al Riyami AM, Mohammed AJ, Jousilahti P. Increasing prevalence of diabetes mellitus in Oman. Diabet Med. 2002;19(11):954-7.

5. Lam DW, LeRoith D. The worldwide diabetes epidemic. Curr Opin Endocrinol Diabetes Obes. 2012;19(2):93-6.

6. Setacci C, de Donato G, Setacci F, Chisci E. Diabetic patients: epidemiology and global impact. J Cardiovasc Surg (Torino). 2009;50(3):263-73.

7. Maia AC, Braga Ade A, Paes F, Machado S, Nardi AE, Silva AC. Psychiatric comorbidity in diabetes type 1: a cross-sectional observational study. Rev Assoc Med Bras. 2014;60(1):59-62.

8. Tareen RS, Tareen K. Psychosocial aspects of diabetes management: dilemma of diabetes distress. Transl Pediatr. 2017;6(4):383-96.
9. Buchberger B, Huppertz H, Krabbe L, Lux B, Mattivi JT, Siafarikas A. Symptoms of depression and anxiety in youth with type 1 diabetes: a systematic review and meta-analysis. Psychoneuroendocrinology. 2016;70:70-84.

10. Ozamiz-Etxebarria N, Dosil-Santamaria M, Picaza-Gorrochategui M, Idoiaga-Mondragon N. Stress, anxiety, and depression levels in the initial stage of the COVID-19 outbreak in a population sample in the northern Spain. Cad Saude Publica. 2020;36(4):e00054020.

11. Mukhtar S. Letter to the Editor: Mental health and psychological distress in people with diabetes during COVID-19. Metabolism. 2020;108:154248.

12. Rubin RR, Peyrot M. Quality of life and diabetes. Diabetes Metab Res Rev. 1999;15(3):205-18.

13. Solli O, Stavem K, Kristiansen IS. Health-related quality of life in diabetes: the associations of complications with EQ-5D scores. Health Qual Life Outcomes. 2010;8:18.

14. Lee WJ, Song KH, Noh JH, Choi YJ, Jo MW. Health-related quality of life using the EuroQol 5D questionnaire in Korean patients with type 2 diabetes. J Korean Med Sci. 2012;27(3):255-60.

15. Sparring V, Nyström L, Wahlström R, Jonsson PM, Ostman J, Burström K. Diabetes duration and health-related quality of life in individuals with onset of diabetes in the age group 15-34 yearsa Swedish population-based study using EQ-5D. BMC Public Health. 2013;13:377.

16. Ahorsu DK, Lin C-Y, Imani V, Saffari M, Griffiths MD, Pakpour AH. The fear of COVID-19 scale: development and initial validation. Int J Ment Health Addict. 2020. https://doi.org/10.1007/ s11469-020-00270-8.

17. Alyami M, Henning M, Krägeloh CU, Alyami H. Psychometric evaluation of the Arabic version of the fear of COVID-19 scale. Int J Ment Health Addict. 2020. https://doi.org/10.1007/ s11469-020-00316-x.

18. Hays RD, Sherbourne CD, Mazel RM. The RAND 36-item health survey 10. Health Econ. 1993;2(3):217-27.

19. Al Abdulmohsin SA. Translation of the RAND 36-item health survey 1.0 (aka SF-36) into Arabic. Vol. 7995. Santa Monica, Calif: RAND; 1997. Print.

20. Zigmond AS, Snaith RP. The Hospital Anxiety and Depression Scale. Acta Psychiatr Scand. 1983;67(6):361-70.

21. El-Rufaie OEFA, Absood G. Validity study of the hospital anxiety and depression scale among a group of Saudi patients. Br J Psychiatry. 1987;151(5):687-8.

22. Lim SL, Woo KL, Lim E, Ng F, Chan MY, Gandhi M. Impact of COVID-19 on health-related quality of life in patients with cardiovascular disease: a multi-ethnic Asian study. Health Qual Life Outcomes. 2020;18(1):387.

23. Rajkumar RP. COVID-19 and mental health: a review of the existing literature. Asian J Psychiatr. 2020;52:102066.

24. Xiong J, Lipsitz O, Nasri F, Lui LMW, Gill H, Phan L, et al. Impact of COVID-19 pandemic on mental health in the general population: a systematic review. J Affect Disord. 2020;277:55-64.

25. Abdelghani M, El-Gohary HM, Fouad E, Hassan MS. Addressing the relationship between perceived fear of COVID-19 virus infection and emergence of burnout symptoms in a sample of Egyptian physicians during COVID-19 pandemic: a cross-sectional study. Middle East Curr Psychiatry. 2020;27(1):1-9.

26. Aljemaiah AI, Osman M, Alharbi S, Alshehri R, Aldggag EM, Aljoudi AT, et al. Fear at the time of the COVID-19 pandemic: validation of the Arabic version of the Four-Dimensional Symptom Questionnaire among Saudi-based respondents. BJPsych Open. 2021;7(1):e33.

27. Abdelghani M, Mahdy RS, El-Gohari HM. Health anxiety to COVID-19 virus infection and its relationship to quality of life in a sample of health care workers in Egypt: a cross-sectional study. Arch Psychiatry Psychother. 2021;1(1):19-28. 
28. Shalash A, Roushdy T, Essam M, Fathy M, Dawood NL, Abushady EM, Elrassas H, Helmi A, Hamid E. Mental health, physical activity, and quality of life in Parkinsons disease during COVID19 pandemic. Mov Disord. 2020;35(7):1097-9. https://doi.org/10. 1002/mds.28134.

29. Abdelghani M, Hassan MS, Alsadik ME, Abdelmoaty AA, Said A, Atwa SA. Post-traumatic stress symptoms among an Egyptian sample of post-remission COVID-19 survivors: prevalence and sociodemographic and clinical correlates. Middle East Curr Psychiatry. 2021;28(1):20. https://doi.org/10.1186/ s43045-021-00102-y.

30. Arafa A, Mohamed A, Saleh L, Senosy S. Psychological impacts of the COVID-19 pandemic on the public in Egypt. Community Ment Health J. 2021;57(1):64-9. https://doi.org/10.1007/ s10597-020-00701-9.

31. Wee HL, Cheung YB, Li SC, Fong KY, Thumboo J. The impact of diabetes mellitus and other chronic medical conditions on healthrelated quality of life: is the whole greater than the sum of its parts? Health Qual Life Outcomes. 2005;3:2.

32. Abedini MR, Bijari B, Miri Z, Shakhs Emampour F, Abbasi A. The quality of life of the patients with diabetes type 2 using EQ-5D-5 L in Birjand. Health Qual Life Outcomes. 2020;18(1):18.

33. Shimels T, Kassu RA, Bogale G, Bekele M, Getnet M, Getachew A, Shewamene Z, Abraha M. Health related quality of life of patients with chronic non-communicable diseases during the coronavirus pandemic in Ethiopia: a multi-facility study. Research Square. 2020. https://doi.org/10.21203/rs.3.rs-108488/v1

34. Arab-Zozani M, Hashemi F, Safari H, Yousefi M, Ameri $\mathrm{H}$. Health-related quality of life and its associated factors in COVID-19 patients. Osong Public Health Res Perspect. 2020;11(5):296-302.

35. Sawalha AH, Zhao M, Coit P, Lu Q. Epigenetic dysregulation of ACE2 and interferon-regulated genes might suggest increased COVID-19 susceptibility and severity in lupus patients. Clin Immunol. 2020;215:108410.

36. Alessi J, De Oliveira GB, Franco DW, Do Amaral BB, Becker AS, Knijnik CP, et al. Mental health in the era of COVID-19: prevalence of psychiatric disorders in a cohort of patients with type 1 and type 2 diabetes during the social distancing. Diabetol Metab Syndr. 2020;12(1):1-10.

37. Czeisler MÉ, Marynak K, Clarke KE, Salah Z, Shakya I, Thierry JM, et al. Delay or avoidance of medical care because of COVID19-related concerns-United States, June 2020. Morb Mortal Wkly Rep. 2020;69(36):1250.

38. Ammar A, Trabelsi K, Brach M, Chtourou H, Boukhris O, Masmoudi L, et al. Effects of home confinement on mental health and lifestyle behaviours during the COVID-19 outbreak: Insight from the "ECLB-COVID19" multi countries survey. MedRxiv. 2020;10227:2-912.

39. Satici B, Gocet-Tekin E, Deniz ME, Satici SA. Adaptation of the fear of COVID-19 scale: its association with psychological distress and life satisfaction in Turkey. Int J Ment Health Addict. 2020. https://doi.org/10.1007/s11469-020-00294-0.

40. Yan AF, Sun X, Zheng J, Mi B, Zuo H, Ruan G, et al. Perceived risk, behavior changes and Health-related outcomes during COVID-19 pandemic: findings among adults with and without diabetes in China. Diabetes Res Clin Pract. 2020;167:108350.

41. Salari N, Hosseinian-Far A, Jalali R, Vaisi-Raygani A, Rasoulpoor $\mathrm{S}$, Mohammadi M, et al. Prevalence of stress, anxiety, depression among the general population during the COVID-19 pandemic: a systematic review and meta-analysis. Glob Health. 2020;16(1):57.

42. Paredes MR, Apaolaza V, Fernandez-Robin C, Hartmann P, Yañez-Martinez D. The impact of the COVID-19 pandemic on subjective mental well-being: the interplay of perceived threat, future anxiety and resilience. Pers Individ Differ. 2021;170:110455.

43. Papadopoulos AA, Kontodimopoulos N, Frydas A, Ikonomakis E, Niakas D. Predictors of health-related quality of life in type II diabetic patients in Greece. BMC Public Health. 2007;7(1):1-9.

44. Zurita-Cruz JN, Manuel-Apolinar L, Arellano-Flores ML, Gutierrez-Gonzalez A, Najera-Ahumada AG, Cisneros-González N. Health and quality of life outcomes impairment of quality of life in type 2 diabetes mellitus: a cross-sectional study. Health Qual Life Outcomes. 2018;16(1):94.

45. Kalda R, Rätsep A, Lember M. Predictors of quality of life of patients with type 2 diabetes. Patient Prefer Adherence. 2008;2:21.

46. Ucan O, Ovayolu N. Relationship between diabetes mellitus, hypertension and obesity, and health-related quality of life in Gaziantep, a central south-eastern city in Turkey. J Clin Nurs. 2010;19(17-18):2511-9.

47. Sharara E, Akik C, Ghattas H, Makhlouf OC. Physical inactivity, gender and culture in Arab countries: a systematic assessment of the literature. BMC Public Health. 2018;18(1):639.

48. Norhammar A, Schenck-Gustafsson K. Type 2 diabetes and cardiovascular disease in women. Diabetologia. 2013;56(1):1-9.

49. Zuberi SI, Syed EU, Bhatti JA. Association of depression with treatment outcomes in Type 2 diabetes mellitus: a cross-sectional study from Karachi, Pakistan. BMC Psychiatry. 2011;11(1):27.

Publisher's Note Springer Nature remains neutral with regard to jurisdictional claims in published maps and institutional affiliations. 